\title{
Una aproximación al paisaje cultural del valle del Mantaro
}

\author{
Enrique Bonilla Di Tolla \\ Universidad de Lima \\ Ingeniería Industrial n. 28, 2010, ISSN 1025-9929, pp. 229-242 \\ Recibido: 8 de junio del 2010 / Aprobado: 16 de julio del 2010
}

\begin{abstract}
RESUMEN: El presente artículo es una aproximación al paisaje cultural del valle del Mantaro, un análisis de sus condiciones naturales y especialmente de la transformación que ha realizado el ser humano a través de la historia. Indaga en el contexto general del territorio y sus poblaciones, para ingresar al estudio de la ciudad de Huancayo, su particular proceso de urbanización, su relación con el valle y sus posibles perspectivas.
\end{abstract}

Palabras clave: paisajes / valle del Mantaro / Huancayo / urbanización

\section{An approximation to the cultural landscape of the Mantaro valley}

\begin{abstract}
The present article is an approximation to the cultural landscape of the Mantaro's valley, an analysis and his natural conditions and specially the transformation that the human being has realized across the history. The general context of the territory analyzes his populations to enter to the study of Huancayo city, his particular process of urbanization, his relation with the valley and his possible future perspectives.
\end{abstract}

Keywords: landscapes / the Mantaro's valley / Huancayo / process of urbanization 
El valle del Mantaro es el valle interandino más grande del Perú y que por su riqueza agrícola y ganadera constituye en la actualidad la despensa de Lima. Asimismo, es un espacio territorial que el hombre ha trabajado y modificado a lo largo de los siglos para el desarrollo de la vida humana.

Este es el aspecto central sobre el que quiero reflexionar en este ensayo: la manera como el ser humano se ha asentado y ha usado este territorio, es decir, cómo se ha configurado el espacio antrópico y lo que últimamente se llama 'paisaje cultural'.

Debo manifestar como advertencia previa, que, a pesar de las referencias bibliográficas de apoyo, este no pretende ser un artículo que presente los resultados de una investigación específica. Es apenas un ensayo basado en experiencias personales, de allí la forma, en primera persona, que uso en su redacción. Tal vez responda a la necesidad de articular una serie de hechos y acontecimientos que me parecen relevantes dentro del contexto geográfico-cultural del valle, como una primera aproximación a una lectura posterior e integral.

Desde el punto de vista territorial, el valle del Mantaro tiene 53 kilómetros de longitud. El ancho es variable, siendo su parte más angosta de 4 kilómetros y la más amplia de 21 kilómetros.

El elemento principal es indudablemente el río Mantaro, que le da nombre al valle. El Mantaro es un río importante dentro de la cuenca del río Apurímac. Gran parte de su larga trayectoria discurre encañonado entre los Andes, excepto cuando cruza el valle. Dicen que en algún momento el río estaba lleno de peces, donde se podían pescar bagres y otras especies, incluso las primeras truchas fueron "sembradas" en sus aguas.

Sin embargo, desde hace muchos años, el Mantaro es un río muerto, debido a que sus aguas están envenenadas por los relaves mineros y sobre todo por la fundición de La Oroya; por eso, en su discurrir por el valle presenta una imagen terrosa rojiza, desastre ecológico que a pesar de varias promesas de planes de protección ambiental (tipo PAMA), aún no tiene solución.

Como elementos constitutivos de su flora podemos mencionar árboles como el quingual (Polylepsis sp), el quishuar (Budleia), el aliso, el molle (Schinus molle) y la tara (Caesalpinea tinctoria), y como arbustos: el chinchilcoma (Mutisia viciaefolia), el marco (Ambrosia peruvia- 
na), la chamana (Dodonaea viscosa), la retama, ${ }^{1}$ el tanquis o mutuy (Cassia), la chilca negra (Fluorencia macrophylla). Sin embargo, el paisaje actual del valle ha sido producto de modificaciones realizadas no hace muchos años. Entre los árboles dominan los eucaliptos, introducidos en el siglo XIX, hacia 1872 aproximadamente, y que no solo han modificado las características del paisaje, sino además las del clima, favoreciendo la agricultura.

No es menos importante la presencia de las plantas cultivadas, como la papa, el maíz, la cebolla, la alcachofa, el haba, el trigo, la cebada, la avena, la col, la calabaza, la lechuga, la zanahoria, la arveja, la betarraga, el apio, el poro, etcétera. Asimismo, existe gran diversidad de frutales: el tumbo, el capulí, la guinda, el manzano, el melocotón, el higo, el ciruelo y el níspero japonés. Además se encuentran variedades de flores: cantutas, rosas, claveles fucsias, copas de oro y muchas más.

En la fauna destaca una gran variedad de pájaros, como el chihuaco (zorzal) y el pichuichanca, pero la mayor parte de la fauna nativa ha sido extinguida por las labores agrícolas, introduciéndose la crianza de ganado vacuno y ovino, y en menor medida cerdos y cabras. La crianza de truchas, traídas en el siglo XX desde Norteamérica, es hoy una de las actividades económicas más importantes de valle.

A pesar de su extensión y su riqueza agrícola actual, es probable que esa riqueza no fuera tan importante en el pasado, esto explicaría por qué el valle del Mantaro no ha sido cuna ni sede de grandes civilizaciones preincaicas. Los sitios arqueológicos, aunque variados, no son muy significativos en el contexto de las grandes culturas que se desarrollaron en nuestro país. El más importante corresponde a un templo que la cultura wari, en su expansión desde Ayacucho, edificó al sur del valle y que recibe el nombre de Warivilca. ${ }^{2}$

Del periodo inca no existen tampoco mayores vestigios. Se sabe que la etnia local, que se denominaba huanca, había sido sometida por los

1 En el caso de la retama, este es un arbusto que también se encuentra en el Mediterráneo, de donde se considera originario. Es posible encontrarlo en varias regiones de España. Podría tratarse de un arbusto introducido en el Perú, ya que el vocablo retama proviene del árabe.

2 En la Crónica del Perú de Pedro Cieza de León (1995), publicada en Sevilla en 1553, se menciona este templo como lo más importante del valle y el único vestigio evidente de los huancas. 
quechuas (incas) del Cusco, cuando Pachacútec empieza la expansión de su imperio, anexando territorios y avasallando a sus poblaciones. Poco después los gobernantes del Cusco construirían su famoso Camino Inca (Capac Nan) que atravesaba el valle de sur a norte. Se dice que uno de los tambos ubicados en la zona sur sería la futura ciudad de Huancayo.

Podríamos inferir que este no era un valle próspero y rico, puesto que no existen evidencias de que lo fuera, y, de haberlo sido, se habría desarrollado una cultura más importante. Los huancas estuvieron muy lejos de otras culturas preíncas y con la excepción del Capac Nan no hay otros vestigios importantes, ni en arquitectura, ni en hidráulica, ni en agricultura tecnificada con andenes, como sí se pueden apreciar en otros valles interandinos, donde la presencia inca es evidente.

Por otro lado, no debe de haber sido muy agradable la convivencia entre quechuas y huancas, por cuanto a la llegada de los conquistadores españoles estos no fueron vistos como tales sino como liberadores de un pueblo sometido, y, si se quiere, atemorizado en ese momento por los ejércitos de los incas de Quito al mando de Atahualpa. Por ello, casi inmediatamente se estableció una alianza entre huancas y españoles, en la que los primeros ayudaron a los segundos en el proceso de conquista.

Quizá esto explique la hospitalidad que los españoles encontraron en el valle, y que unido a las características del clima, propio de la región quechua, con clima seco y templado, los llevara primero a instalarse en 1533 en un caserío al que los huancas llamaban Hatum Xauxa y que los españoles denominaron Jauja. El nombre está asociado al mito ibérico del "País de Jauja" o el lugar de la abundancia, que aún hoy es parte del imaginario infantil del mundo iberoamericano, y que ha dado lugar a la frase de uso corriente en España y gran parte de América, "esto es Jauja”, como sinónimo del lugar de la facilidad y la riqueza.

\section{LA LLEGADA DE LOS CONOUISTADORES}

Sobre este asentamiento, el conquistador Francisco Pizarro decide fundar la ciudad de Jauja como capital del territorio conquistado, el 24 de abril de 1534. El acontecimiento no sería tan importante si no se explicara que esta fundación se produjo luego del periplo que el conquistador realizara por el sur del Perú y la correspondiente toma del Cusco, que luego sería refundada como ciudad española en el mismo 
1534, pero que no sería escogida como la capital de los territorios dominados. La primacía de Jauja se debe, tal vez, a razones que podemos atribuir a la hospitalidad o en todo caso a la no hostilidad de los huancas y a las posibilidades de agua y agricultura que el valle del Mantaro ofrecía. Aun así, la vigencia de esta capital fue bastante efímera, porque menos de un año después, el 18 de enero de 1535, Pizarro fundó otra ciudad como nueva y definitiva capital del Virreinato: la "Ciudad de los Reyes", a la que más tarde se le llamará Lima.

En el interior del valle del Mantaro, aproximadamente 45 kilómetros al sur, en un sitio que para la civilización huanca había tenido un valor religioso por la presencia de un oráculo o una divinidad (huamán), y donde, como he señalado, los quechuas establecieron un tambo: otra ciudad se comenzaba a gestar. Sin la bendición de una fundación española,${ }^{3}$ pero favorecida por el encuentro de los caminos y los comerciantes que viniendo del norte se bifurcan hacia el sur y hacia el selvático oriente, aparecerá, cual burgo medieval europeo, un nuevo pueblo que se llamará Huancayo, y que luego rivalizará con Jauja por la hegemonía del valle del Mantaro.

Casi se podría decir que la historia urbana del valle del Mantaro se construyó a partir del devenir de estas dos ciudades. Jauja será la ciudad de abolengo, que no olvidará jamás haber sido la primera capital del Perú. Lo atestiguan su ordenada trama hispánica de manzanas y Plaza de Armas. Huancayo, mientras tanto, deberá su origen al camino y dependerá de él para su estructuración urbana; la famosa calle Real será, hasta bien entrado el siglo XX, el eje o columna vertebral de la ciudad. Las plazas huancaínas, como la de Huamanmarca (actual Centro Cívico), tendrán un origen místico religioso, que luego devendrá en comercial. La primera Plaza de la Constitución corresponderá a una expropiación de una manzana ${ }^{4}$ para conmemorar la Constitución Liberal Española de las Cortes de Cádiz, que se jurara en 1812 en esta ciudad.

3 Este asunto es polémico. Algunos hablan de una fundación española hacia 1572 y otros simplemente de una advocación de la ciudad al Espíritu Santo. Estoy de acuerdo con lo segundo, pues una fundación española, de acuerdo con el modelo pragmático y las leyes de Indias, hubiera significado contar con una Plaza Mayor o de Armas y una trama. Huancayo carece de ambas.

4 La actual plaza de la Constitución corresponde a una segunda expropiación y demolición de una manzana vecina, ubicada entre la calle Real, la avenida Giráldez y la calle Ancash. De esta manera, la pequeña plaza pudo, en 1972, durante la gestión del alcalde Julio Bonilla García, duplicar su extensión. 
Así como no hay vestigios prehispánicos importantes, tampoco la Conquista ha dejado grandes huellas en las ciudades del valle. A diferencia de otras ciudades andinas como Arequipa, Cajamarca o la cercana Ayacucho, no hay una presencia importante de arquitectura virreinal. Es acaso esto producto de la poca presencia hispana en el valle o tal vez las excesivas concesiones que los españoles dieron a los huancas. Se sabe, por ejemplo, que desde los inicios de la Colonia existieron en el valle indios encomenderos, situación solo reservada para los españoles.

No existe tampoco, ni en Jauja ni en Huancayo, ni templos ni conventos de las principales órdenes religiosas, como sí los hay en las otras ciudades andinas ya mencionadas. La solitaria presencia de la iglesia y el convento de los franciscanos en el vecino pueblo de Santa Rosa de Ocopa es bastante tardía, data del siglo XVIII ${ }^{5}$ y fue establecida como un puesto de avanzada del proceso de evangelización de la selva central.

Las guerras decimonónicas tendrán en el valle del Mantaro un escenario muy particular. Jauja y Huancayo serán de las primeras ciudades peruanas en jurar la Constitución Española de las Cortes Cádiz de 1812 y Huancayo jurará la independencia del Perú el 20 de noviembre de 1820, meses antes que lo haga Lima. Por ese motivo, durante el gobierno de Torre Tagle en 1822 se le daría el título de "Ciudad Incontrastable". Sin embargo, durante el proceso de la independencia, libertarios y realistas se alternaron en la posesión del valle, hasta que la independencia fuera sellada en 1824 .

\section{EL VALLE DEL MANTARO EN LA GUERRA DEL PACÍFICO}

A la presencia de las tropas durante las guerras de la Independencia se le atribuye la aparición de la famosa Feria Dominical de Huancayo, por ser el lugar de compras y abastecimiento de los soldados de uno y otro bando. Más tarde, y debido a su privilegiada ubicación geográfica de encuentro de caminos, esta situación se verá potenciada y la marcará como el primer centro comercial y de servicios que es hasta hoy.

5 El convento de Santa Rosa de Ocopa fue fundado en 1725, por el fraile franciscano Francisco de San José. 
La Guerra del Pacífico entre Chile y Perú tuvo uno de sus episodios más cruentos en el valle del Mantaro, teatro de operaciones de la denominada Campaña de la Breña, donde las montoneras de Cáceres enfrentaron exitosamente al ocupador ejército chileno. Gran parte del imaginario de los pueblos del valle está centrado en la épica campaña de Cáceres y sus célebres avelinos, que infligieron sendas derrotas al ejército invasor en las batallas de Concepción, Pucará y Marcavalle. Recuerdo, como creo que todos los niños del valle del Mantaro lo hemos hecho, haber disfrutado con los relatos de mi abuela y sus hermanos, así como de los profesores del colegio, episodios cargados de heroísmo y de personajes míticos, que reforzaban nuestro patriotismo infantil. Pero, por otro lado, evidenciaban que las heridas que había dejado la Guerra del Pacífico eran profundas y no habían cicatrizado.

Más tarde, en los años universitarios, la lectura del estupendo texto de Nelson Manrique (1981) sobre las guerrillas indígenas de la Guerra del Pacífico me dieron otra visión más racional de la Campaña de la Breña. Tal vez el aspecto más significativo es que esta supuso la casi destrucción de la próspera economía del valle del Mantaro, que había alcanzado - tanto en el sector agrícola como en el pecuario- un alto desarrollo. Sostener dos ejércitos durante dos años afectó seriamente las haciendas de la región, cuyo proceso de recuperación fue sumamente lento.

Sin embargo, es la Guerra del Pacífico la que establece un punto de inflexión en el desarrollo de los pueblos y las posteriores ciudades del valle del Mantaro. Muchos historiadores sostienen que la guerra con Chile marcó la identidad del pueblo peruano y asentó la nacionalidad de uno y otro bando, uno como vencedor y otro como vencido. Sin embargo, esta relación se invierte en el valle del Mantaro, donde las derrotas del ejército chileno arrojan un saldo positivo para el Perú. En buena cuenta, dentro del desastre nacional, la Campaña de la Breña asoma como un episodio exitoso y será muy importante para levantar la autoestima de los pueblos del valle, terminando por definir esa identidad que ha sostenido la pujanza que se evidenciará en el siglo XX.

A fines del siglo XIX, y probablemente hasta la primera mitad del siglo XX, las ciudades del valle del Mantaro, especialmente Jauja, se harán conocidas debido a las bondades de su clima para la cura de las enfermedades respiratorias, en especial el asma y la tuberculosis. Cientos de enfermos, sin distingo de condición social ni nacionalidad, se tras- 
ladaban a Jauja para encontrar alivio a sus males. Se construyó para tal fin el hospital Olavegoya, notable muestra de nosocomio de tipología pabellonal, ${ }^{6}$ regentado por las religiosas galas de San Vicente de Paúl, con su célebre toca alada. Más tarde, gracias a las donaciones de los enfermos agradecidos, se construiría el famoso templo de Cristo Pobre, una pieza neogótica enclavada en el corazón de los Andes.

La presencia de una gran cantidad de población foránea, en buena parte extranjera, dotó a Jauja de un carácter muy especial. A su tradición de ciudad española se vino a sumar un cosmopolitismo muy particular, que recoge con mucha acuciosidad Edgardo Rivera Martínez en su novela País de Jauja. ${ }^{7}$ Planteada desde la perspectiva de un adolescente que descubre el amor en unas vacaciones escolares de verano, nos presenta la dualidad del universo jaujino donde el mundo occidental y el andino se van superponiendo, produciendo una simbiosis pacífica entre estos dos mundos que algunos han considerado antagónicos.

El carácter humanista e intelectual de Jauja contrasta con el pragmatismo de Huancayo, en especial desde la llegada del Ferrocarril Central a esta última, en la primera década del siglo $\mathrm{XX}$, que produjo un desarrollo industrial en varios rubros: curtiembres, cervecería y, fundamentalmente, industria textil. Se dice que los jaujinos, cual románticos europeos, rechazaron la presencia de la industria en su ciudad por considerarla contaminante y nociva. Esta situación favoreció a Huancayo, que a su característico empuje comercial sumó el de centro industrial.

En la lectura de las dos ciudades importantes del valle, solía decirse, a principios del siglo XX, que una —Jauja- por su vocación cosmopolita y marcadamente intelectual era la Atenas; mientras que Huancayo por su fuerza y empuje parecía una moderna Esparta. Muy pronto - como sucedió también en Grecia - la fuerza de una se impondría a la de la otra, y en la segunda mitad del siglo XX será Huancayo la que tome la delantera empinándose como la tercera ciudad del Perú, lugar que disputa con Chiclayo, detrás de Arequipa y Trujillo.

6 Esta tipología tiene su primer antecedente conocido en el hospital de San Bartolomé, en Londres. El nosocomio posee una larga trayectoria, desde 1730 hasta el presente.

7 País de Jauja fue considerada por la crítica como la mejor novela de la década de 1990 y es hoy una de las piezas fundamentales de la literatura peruana contemporánea. 
En el siglo XX, Huancayo habrá pasado de unos pocos miles hasta llegar al medio millón de habitantes al iniciar el siglo XXI. Si la comparamos con las otras ciudades del Mantaro, la Incontrastable cuadriplica la población de Jauja y multiplica por seis la de Concepción, las otras ciudades del valle. Esta concentración poblacional presenta, a escala de la microrregión, el mismo modelo de macrocefalia que Lima ofrece en el ámbito nacional. Podríamos aplicar para el caso la teoría de los fractales, donde un mismo sistema se reproduce a diversas escalas, pues es en esencia el mismo.

En los párrafos que siguen centraré mis reflexiones en la ciudad de Huancayo, la más importante del valle.

\section{HUANCAYO Y SU IMPORTANCIA EN EL VALLE DEL MANTARO}

El origen bastante peculiar de esta ciudad ha dado lugar a una muy particular historia. Si aceptamos que la ciudad es un ser vivo, podríamos establecer que una ciudad tiene una biografía. ${ }^{8}$ En toda biografía que se respete, hay aspectos saltantes, que se pueden presentar en el nacimiento, en la infancia, la juventud o acaso la adultez. En Huancayo, como he tratado de explicar, no será importante ni su nacimiento o acaso fundación en el siglo XVI, ni sus primeros años durante la Colonia, cuando no pasa de ser un caserío de menor importancia.

Ya he mencionado cómo podríamos establecer su real aparición en la gesta de la Emancipación, cuando debido al valor de sus gentes en las guerras de la Independencia, adquirió la categoría de ciudad y el adjetivo de Incontrastable. Por eso, Huancayo es una expresión urbana genuinamente republicana, cuando el caserío se convierte en urbe debido a la importancia comercial que adopta como punto de encuentro de costa, sierra y selva central en la Feria de Huancayo. ${ }^{9}$ Por lo tanto, es en esencia una ciudad peruana.

8 Así ha titulado su libro de historia de Huancayo el arquitecto Luis Samalvides: Huancayo, biografía de una ciudad (Samalvides 2005).

9 Es importante señalar que el tema de la Feria Dominical de Huancayo ha merecido la atención y el estudio de varios antropólogos y etnólogos. El caso más importante es el de José María Arguedas, quien en 1958 se ocupó del asunto. Sobre este y otros aspectos relacionados con Arguedas y el valle del Mantaro, la socióloga Carmen María Pinilla ha recopilado varios ensayos en el texto Arguedas en el valle del Mantaro (Pinilla 2004). 
Por otro lado, es también una ciudad que en menos de dos siglos de vida republicana alcanza un gran crecimiento y desarrollo. A pesar de lo accidentado de nuestra historia decimonónica, plagada de guerras internas y externas y la enorme repercusión de estas sobre los prósperos pueblos del valle del Mantaro, la pujanza huancaína habrá de superar a todas las otras ciudades de la región.

Pero no será hasta el siglo XX que Huancayo establecerá esa relación con la modernidad que la ha marcado tanto. Como ya he mencionado, la llegada del ferrocarril, la aparición de las primeras industrias, la construcción de la Carretera Central, entre otros acontecimientos, unidos al extraordinario crecimiento del sector comercial que no se limitará solo a la tradicional Feria Dominical, sino a establecimientos permanentes que poco a poco irán consolidando la Calle Real como un eje económico que se irradiará a los jirones aledaños.

Con relación al proceso urbano de esta ciudad, ensayaré algunos comentarios. Es verdad que en todas las ciudades hay un presente, pero se respeta el pasado y se prevé el futuro, pero en Huancayo solo el presente importa. Se maneja con la lógica del comerciante que siempre quiere la mayor rentabilidad, y si es rápido mejor. Esto se observa en la arquitectura de la ciudad, donde las edificaciones sufren permanentes transformaciones y adecuaciones comerciales y cuando están casi por colapsar o colapsan son sustituidas por modernos edificios que casi siempre reservan una primera planta para locales comerciales.

Tal vez la idea de la permanencia no exista. Huancayo se mueve con una lógica de puesto de feria — no por gusto se le llama la "capital ferial" - donde las cosas son efímeras; se instalan y desinstalan el mismo día, como la carpa de un nómade. Por ello, aquí todo el mundo anda de paso y la idea de permanecer no existe, lo cual se refleja en la urbe y, por cierto, en la arquitectura. En el nivel urbano esto explicaría también por qué esta ciudad tiene una densidad tan baja: setenta y seis habitantes por hectárea. Otro indicador es su falta de consolidación, las habilitaciones urbanas son menos que rústicas y un gran porcentaje de sus calles carece de pistas y veredas. En términos urbanos es casi un campamento, un inmenso campamento depredando la zona agrícola.

Hace unos años, a raíz de los ensanches de la sección de las calles del área central, que cambiaron a mediados de los noventa la fisonomía de la ciudad, encontré pocos detractores de la medida. La mayoría 
estaba a favor, consideraba que estas intervenciones eran un signo de progreso. Era necesario tener calles más amplias para permitir que los vehículos circulen mejor. No importaba el valor patrimonial que tuvieran, como tampoco si había dinero para reconstruir las edificaciones. Recuerdo que durante un tiempo las edificaciones fueron cortadas de tal manera que parecía que al edificio le habían sacado las entrañas.

Cuando una ciudad prioriza tanto su circulación, la idea de estar y probablemente de ser y permanecer desaparece. Esto me lleva a concluir que el espíritu conservador en Huancayo es muy limitado, circunscrito a poquísimos espacios románticos. Entre estos está el Arzobispado, ${ }^{10}$ que con acierto logró salvar uno de los frentes de la Plaza de la Constitución.

Revisando la historia urbana de Huancayo, escrita por Luis Samalvides (2005), infiero que esa es una constante histórica: la permanente apuesta por el puro presente. No hay casi edificios históricos en la ciudad y espero que los pocos que quedan, como la casa de la familia Ráez, en la calle Ica, o la casa de la familia Peñaloza, en la calle Real, puedan dar testimonio de una época de la ciudad del siglo XIX y principios del siglo XX, respectivamente. Espero también que la Catedral se mantenga y no corra la suerte de la vieja iglesia matriz, la famosa Cututorre (torre trunca), de la que hablaban las abuelas, sustituida por un "neocolonial" hotel "Turismo", como se denomina actualmente al antiguo Hotel de Turistas.

Por ello, creo que el verdadero patrimonio de la ciudad es el que en este momento se ha gestado o se está gestando. Me atrevería a decir que Huancayo es, dentro del contexto de las ciudades peruanas, la que mejor encarna a la ciudad moderna o es en sí misma la modernidad urbana, en su versión nacional. Ahora que se puede decir estas cosas sin pudor, me pregunto: ¿no es acaso la Incontrastable el prototipo de una ciudad capitalista?, regida absolutamente por las lógicas del mercado que le otorga esa dinámica tan particular que aprecian los visitantes. Considero que, de las ciudades peruanas, Huancayo es una de las más cosmopolitas y la más cercana a esa imagen de ciudad global

10 En la década de 1990 el Arzobispado emprendió una decidida acción por la conservación del patrimonio cultural de su Arquidiócesis. 
que caracteriza a la urbe contemporánea y que tanto aprecian las vanguardias arquitectónicas situadas en la deconstrucción, la dispersión, el fragmentarismo y el caos.

Huancayo ha jugado su suerte por la modernidad y eso tal vez será importante en el futuro. Estoy casi convencido de que quizás, si algún patrimonio monumental tiene Huancayo, este corresponde al siglo XX, como el Centro Cívico del arquitecto Correa Miller, de lejos el conjunto arquitectónico más representativo e imagen de la ciudad. Pero tal vez este patrimonio esté aún por construirse y corresponderá acaso al siglo XXI. Es su derecho, como el de Lima es el del siglo XVIII, el de Florencia el del siglo XVI, el de Buenos Aires el de principios del siglo XX. En ninguno de los casos corresponde a la época de la fundación, sino al del máximo esplendor de cada una de las ciudades. Huancayo es, en el contexto de las ciudades peruanas, una ciudad joven, que apenas ha pasado la adolescencia. La ausencia de tiempo, es decir la ucronía, nunca es un demérito, es una realidad que hay que asumir para realizar la adecuada construcción de la ciudad.

Mientras tanto, tenemos que empezar también a descubrir el pasado que nos permita describir un proceso histórico-urbano que irá formando poco a poco la memoria viva de la ciudad. Que vaya dejando testimonio de cada época, con sus inquietudes y sus vicisitudes. Las ciudades, para ser grandes, necesitan entenderse no solo para preservarse, sino para proyectarse con seguridad al mañana.

Pero Huancayo debe también entender que su relación más importante es con el valle y juntamente con las otras ciudades —Jauja y Concepción - que integran ese microsistema urbano, debe apuntar a un equilibrio ambiental entre lo urbano y lo rural, entre la ciudad y su entorno. El crecimiento demográfico y la extensión del continuo urbano de Huancayo con su bajísima densidad, corre el peligro de conurbarse, como ya lo viene haciendo, con algunos pueblos cercanos como Concepción, y en un futuro no tan lejano con Jauja.

Por ello, será necesario que los pueblos del valle, en algo que hoy se llama la mancomunidad, marchen en conjunto hacia un plan urbanoambiental que permita mantener el equilibrio hombre-medioambiente. Solo así puede ser entendida la construcción de un paisaje cultural del siglo XXI, donde el patrimonio construido y el espacio natural se manejen de una manera respetuosa y como lo que son: artificio y naturaleza. 
Hay una frase de una canción popular que dice: "yo soy huancaíno por algo". ${ }^{12}$ Alguna vez, otro huancaíno, el arquitecto Luis Rodríguez Cobos, me hizo notar que ese "algo" no era explicado y nadie sabe qué es. Tal vez algún día el huanca pueda cambiar ese "algo" por algo que lo enorgullezca. La sensación es que aún no lo ha encontrado, o mejor, que lo está construyendo.

De la misma manera, creo que Huancayo, Ciudad Incontrastable, es solo una frase que a varios les cuesta explicar. Mas allá de su connotación histórica ¿que significa incontrastable? Según el diccionario Larousse (2005: 555) tiene dos significados: que no se puede impugnar o discutir con argumentos sólidos; y que no se deja reducir o convencer.

A pesar de ir contra todas las reglas, la urbanidad de Huancayo es difícil de discutir con argumentos. Sé que tampoco la podremos convencer de que enmiende un rumbo, que los arquitectos y urbanistas debemos primero saber entender, para luego tal vez proponer.

Pero es necesario hoy no solo construir la ciudad, sino además construir un paisaje resultante del respeto entre lo natural y lo cultural. Para eso, los pueblos del Mantaro, y en especial Huancayo, deberán volver la mirada hacia sí mismos y reconciliarse con su hermoso valle, que dicen es el valle interandino más grande del Perú. Ojalá lo sea para siempre.

\section{BIBLIOGRAFÍA}

Cieza de León, Pedro (1995). Crónica del Perú. Lima: Pontificia Universidad Católica del Perú, Fondo Editorial [1553].

Larousse (2005). El pequeño Larousse ilustrado. México, D. F.: Ediciones Larousse.

Manrique, Nelson (1981). Campesinado y nación. Las guerrillas indígenas en la guerra con Chile. Lima: Centro de Investigación y Capacitación/Editora Ital Perú.

12 Tomada del huaino Yo soy huancaíno, compuesto por Zenobio Daga e interpretado por Víctor Alberto Gil, el Picaflor de los Andes. 
Pinilla, Carmen María et al. (2004). Arguedas en el valle del Mantaro. Lima: Pontificia Universidad Católica del Perú, Fondo Editorial.

Rivera Martínez, Edgardo (2001). País de Jauja. Lima: Peisa.

Samalvides Santillana, Luis (2005). Huancayo. Biografía de una ciudad. Huancayo: Colegio de Arquitectos del Perú - Junín, Consejo Regional Sierra Central. 